\title{
The Extent of Desmoglein 3 Depletion in Pemphigus Vulgaris Is Dependent on $\mathrm{Ca}^{2+}$-Induced Differentiation
}

\section{A Role in Suprabasal Epidermal Skin Splitting?}

\author{
Volker Spindler, ${ }^{, \dagger}$ Alexander Endlich, ${ }^{*}$ \\ Eva Hartlieb, ${ }^{\star \dagger}$ Franziska Vielmuth, ${ }^{*}$ \\ Enno Schmidt, ${ }^{\neq \S}$ and Jens Waschke ${ }^{* \dagger}$ \\ From the Institute of Anatomy and Cell Biology, University of \\ Würzburg, Würzburg; the Institute of Anatomy and Cell \\ Biology, ${ }^{\dagger}$ Ludwigs-Maximilians-University, Munich; and the \\ Department of Dermatology $y^{\ddagger}$ and the Comprehensive Center for \\ Inflammation Medicine, ${ }^{\S}$ University of Lübeck, Lübeck, Germany
}

Pemphigus vulgaris (PV) is an autoimmune disease of the skin and mucous membranes and is characterized by development of autoantibodies against the desmosomal cadherins desmoglein (Dsg) 3 and Dsg1 and formation of intraepidermal suprabasal blisters. Depletion of Dsg3 is a critical mechanism in PV pathogenesis. Because we did not detect reduced Dsg3 levels in keratinocytes cultured for longer periods under high- $\mathrm{Ca}^{2+}$ conditions, we hypothesized that Dsg depletion depends on $\mathrm{Ca}^{2+}$. mediated keratinocyte differentiation. Our data indicate that depletion of Dsg3 occurs specifically in deep epidermal layers both in skin of patients with PV and in an organotypic raft model of human epidermis incubated using IgG fractions from patients with PV. In addition, Dsg 3 depletion and loss of Dsg3 staining were prominent in cultured primary keratinocytes and in HaCaT cells incubated in high-Ca ${ }^{2+}$ medium for 3 days, but were less pronounced in HaCaT cultures after 8 days. These effects were dependent on protein kinase $C$ signaling because inhibition of protein kinase $\mathrm{C}$ blunted both Dsg3 depletion and loss of intercellular adhesion. Moreover, protein kinase $\mathrm{C}$ inhibition blocked suprabasal Dsg3 depletion in cultured human epidermis and blister formation in a neonatal mouse model. Considered together, our data indicate a contribution of Dsg depletion to PV pathogenesis dependent on $\mathrm{Ca}^{2+}$-induced differentiation. Fur- thermore, prominent depletion in basal epidermal layers may contribute to the suprabasal cleavage plane observed in PV. (AmJ Pathol 2011, 179:1905-1916; DOI: 10.1016/j.ajpath.2011.06.043)

Pemphigus is an autoimmune skin disease characterized by erosions and blisters in mucous membranes and the epidermis. ${ }^{1}$ Loss of intercellular keratinocyte adhesion (termed "acantholysis") is primarily caused by autoantibodies directed against the integral desmosomal adhesion molecules desmoglein (Dsg) 3 and Dsg1. ${ }^{2}$ In the most frequent variant, pemphigus vulgaris (PV), affection of mucous membranes is associated with autoantibodies against Dsg3 only, whereas additional Dsg1 autoantibodies also induce blistering within the epidermis. In another common variant, pemphigus foliaceus (PF), autoantibodies develop against Dsg1 only, leading to epidermal blistering only. Intraepidermal blisters in PV occur strictly in the suprabasal layers, whereas in PF, the cleavage plane is located in the superficial granular layer. Within the epidermis, there is a distinct distribution of the PV antigens Dsg3 and Dsg1. ${ }^{3}$ Dsg3 localizes to all layers except the granular and cornified layers. In contrast, Dsg1 is most prominent in the granular layer, and is less abundant in the spinous and basal layers. This differential expression of Dsgs within the epidermis led to the proposition of the desmoglein compensation theory, based on direct inhibition of desmoglein transinteraction induced by autoantibody binding. ${ }^{1,4}$ In this setting, superficial blistering in PF occurs because of the absence of Dsg3 in

Supported by Deutsche Forschungsgemeinschaft (SFB 487, TB B5).

Accepted for publication June 22, 2011

Supplemental material for this article can be found on http://ajp. amjpathol.org or at doi: 10.1016/j.ajpath.2011.06.043

Address reprint requests to Jens Waschke, M.D., Institute of Anatomy and Cell Biology, Pettenkoferstrasse 11, D-80336 Munich, Germany. E-mail: jens.waschke@med.uni-muenchen.de. 
the granular layer, whereas in deeper layers, Dsg3 compensates for the loss of Dsg1 transinteraction mediated by PF antibodies. Similarly, suprabasal blistering in PV is explained by this theory because in cutaneous PV, both Dsg1 and Dsg3 autoantibodies are present, and, thus, none of the Dsgs are able to compensate for the others. This hypothesis is supported, at least in part, by our studies using recombinant desmogleins, which demonstrated direct inhibition of homophilic Dsg3 transadhesion by IgG fractions of $P V$ patients ( $P V / g G$ ) but detected no evidence for inhibition of homophilic Dsg1 binding. 5,6 However, it was observed that PF IgG containing autoantibodies against Dsg1 but not against Dsg3 were also effective in causing epidermal cleavage in human skin and keratinocyte dissociation in vitro, ${ }^{7}$ which indicates that Dsg 1 and Dsg3 are not likely to fully compensate for each other, again raising the question of why cleavage in PV is restricted to the suprabasal plane.

In addition to direct inhibition, a plethora of signaling pathways are altered after application of PV IgG both in cultured keratinocytes and in animal studies. P38MAPK activation is a key event in PV IgG-induced loss of cell adhesion in vitro and in vivo and in patients with $\mathrm{PV} .{ }^{8,9}$ Similarly, signaling by Rho GTPases and plakoglobin is altered, and other mechanisms such as epidermal growth factor receptor signaling or keratinocyte apoptosis have been discussed. ${ }^{10-15}$

Depletion of Dsg3 levels occurs in patient skin, in vivo in mouse models of PV, and in vitro in cultured keratinocytes, and, thus, has been thought to weaken intercellular adhesion by destabilizing desmosomes. ${ }^{16-20}$ In addition, Dsg3 depletion has been linked to the well-established p38MAPK pathway in PV. ${ }^{21}$ Many in vitro studies have been performed using primary keratinocytes that were maintained in low- $\mathrm{Ca}^{2+}$ medium for proliferation and were switched to high- $\mathrm{Ca}^{2+}$ medium for relatively short periods (4 to 24 hours) to induce $\mathrm{Ca}^{2+}$-dependent differentiation and cell contact formation. In our studies using $\mathrm{HaCaT}$ keratinocytes maintained in high- $\mathrm{Ca}^{2+}$ medium typically for longer than 5 days, pronounced depletion of either cytoskeleton-linked or non-cytoskeleton-bound Dsg3 levels was not observed. ${ }^{14}$ Therefore, in the present study, we investigated whether Dsg3 depletion may be dependent on $\mathrm{Ca}^{2+}$-induced differentiation in cultured keratinocytes. Since basal keratinocytes are rather undifferentiated compared with keratinocytes of the granular layer, we evaluated whether Dsg 3 depletion in basal keratinocytes may contribute to the suprabasal cleavage plane observed in PV. Because signaling by protein kinase $C(P K C)$ has been considered to mediate intercellular adhesion, we tested in cell culture, epidermis models, and the neonatal mouse model the role of PKC in depletion induced by PV-IgG.

\section{Materials and Methods}

\section{Cell Culture and Test Reagents}

Spontaneously immortalized keratinocytes ( $\mathrm{HaCaT}$ ) were seeded at a density of $3 \times 10^{4}$ cells $/ \mathrm{cm}^{2}$. HaCaT cells were maintained for indicated times in Dulbecco's modified Eagle's medium supplemented with 10\% fetal calf serum (Biochrom AG, Berlin, Germany), $50 \mathrm{U} / \mathrm{mL}$ penicillin $\mathrm{G}$, and $50 \mu \mathrm{g} / \mathrm{mL}$ streptomycin in a humidified atmosphere containing $5 \% \mathrm{CO}_{2}$ at $37^{\circ} \mathrm{C}$. Normal human keratinocytes derived from breast explants were purchased from PromoCell GmbH (Heidelberg, Germany) and cultured in keratinocyte growth medium containing supplement mix (both from PromoCell $\mathrm{GmbH}$ ). Cells were seeded at a density of $5 \times 10^{3}$ cells $/ \mathrm{cm}^{2}$ and were maintained in low- $\mathrm{Ca}^{2+}$ medium $(0.15 \mathrm{mmol} / \mathrm{L})$ until confluence was reached. Cells were transferred to high-Ca ${ }^{2+}$ medium $(1.8 \mathrm{mmol} / \mathrm{L})$ with addition of $\mathrm{CaCl}$ for 24 hours before the experiments were started.

The inhibitor of the classic PKC isoforms Gö6976 (SigmaAldrich, München, Germany) was used at $500 \mathrm{nmol} / \mathrm{L}$ for 24 hours unless stated otherwise. The PKC $\alpha$ inhibitor safingol (EMD Biosciences, Inc., division of Merck KGaA, Darmstadt, Germany) was applied at $40 \mu \mathrm{mol} / \mathrm{L}$ for the same periods.

\section{Small-Interfering RNA-Mediated Knockdown of $P K C \alpha$}

PKC $\alpha$-specific small-interfering RNA (Hs-PRKCA-5) was purchased from Qiagen GmbH (Hilden, Germany), and non-targeting small-interfering RNA (D-001810-0X) from Dharmacon, Inc. (Chicago, IL). HaCaT cells were seeded in 12-well plates, and small-interfering RNA was transfected after 24 hours using an in vitro transfection reagent (Turbofect; Fermentas GmbH, St. Leon-Rot, Germany) according to the manufacturer's instructions. At 24 hours after transfection, cells were incubated using PV IgG for 24 hours. Cells were harvested for Western blot analysis or subjected to dissociation assays.

\section{Purification and Preparation of Patient lgG}

Serum samples from three patients with PV were used in the study. All patients with PV exhibited widespread erosions when blood was taken, and demonstrated typical findings at histopathologic analysis of a lesion biopsy specimen and direct immunofluorescence microscopy of a perilesion biopsy specimen. The autoantibody profiles as determined using enzyme-linked immunosorbent assay (ELISA) measurements (Euroimmun Medizinische Labordiagnostika AG, Lübeck, Germany) are given in Table 1. IgG fractions were prepared using protein $A$ affinity chromatography as previously described. ${ }^{6}$ For in vitro experiments, PV1 IgG and PV2 IgG were used in parallel, and yielded essentially the same results. Con-

Table 1. Autoantibody Profile of Patient IgG

\begin{tabular}{ccc}
\hline ELISA values & Dsg3 $(\mathrm{U} / \mathrm{mL})$ & Dsg1 $(\mathrm{U} / \mathrm{mL})$ \\
\hline PV1 IgG & 6586 & Negative \\
PV2 IgG & 1239 & 60 \\
PV3 IgG & 1185 & 977 \\
\hline
\end{tabular}

Dsg, desmoglein; PV, pemphigus vulgaris. 
Table 2. Autoantibody Profile of Patients with PV

\begin{tabular}{ccc}
\hline ELISA values & Dsg3 $(\mathrm{U} / \mathrm{mL})$ & Dsg1 $(\mathrm{U} / \mathrm{mL})$ \\
\hline PV patient 1 & 787 & 656 \\
PV patient 2 & 1098 & 535 \\
\hline
\end{tabular}

Dsg, desmoglein; PV, pemphigus vulgaris.

centrations of both IgG fractions used throughout the experiments were adjusted to $500 \mu \mathrm{g} / \mathrm{mL}$. For the in vivo mouse model, only PV3 IgG was used, at a concentration of $6 \mathrm{mg} / \mathrm{mL}$.

\section{Skin Biopsy of Patients with PV and Processing of Cryosections}

Perilesion skin biopsy specimens were obtained from two patients with $\mathrm{PV}$ before treatment was initiated and from two healthy volunteers. Patient autoantibody profiles are given in Table 2. After brief rinsing with PBS, the skin specimens were mounted on copper plates using Reichert-Jung mounting medium (Cambridge Instruments $\mathrm{GmbH}$, Nussloch, Germany) and frozen in liquid nitrogen. Cryosections $5 \mu \mathrm{m}$ thick were obtained using a ReichertJung 2800 Frigocut cryostat (Cambridge Instruments $\mathrm{GmbH}$ ) and transferred to glass slides. Sections were dried on a heater at $37^{\circ} \mathrm{C}$ for 30 minutes, followed by washes with PBS and permeabilization with $0.1 \%$ Triton $X-100$ in PBS for 1 hour. After two additional rinses with PBS, sections were blocked using 3\% bovine serum albumin and $1 \%$ normal goat serum. Sections were stained for Dsg3 using a monoclonal antibody directed against the extracellular domain (clone 5G11; diluted 1:100 in PBS; Invitrogen $\mathrm{GmbH}$, Darmstadt, Germany) at $4^{\circ} \mathrm{C}$ overnight. For some experiments, a rabbit polyclonal Dsg3 antibody against the C-terminal (intracellular) end was applied (clone $\mathrm{H}-145$; diluted 1:100 in PBS; Santa Cruz Biotechnology, Inc., Santa Cruz, CA). As secondary antibodies, Cy3-linked goat anti-mouse or goat anti-rabbit antibodies (both from Dianova GmbH, Hamburg, Germany) were used at a dilution of 1:600 for 1 hour at room temperature. Alternatively, bound PV IgG was detected using a Cy3-linked goat anti-human antibody (Dianova $\mathrm{GmbH}$ ) under the same conditions.

\section{Human Skin Models}

The ex vivo model of human skin was used as described previously. ${ }^{7}$ In brief, skin biopsy specimens were obtained from recently deceased humans who had donated their body to the Institute of Anatomy and Cell Biology for teaching and science purposes. Viability of the skin was ensured via parallel incubation with MTT [1-(4,5-dimethylthiazol-2-yl)-3,5-diphenylformazan]. Specimens were transferred to 96-well plates and incubated with Dulbecco's modified Eagle's medium with or without PV IgG (500 $\mu \mathrm{g} / \mathrm{mL}$ ) for 24 hours.

Organotypic epidermal raft models (model EST-1000) were purchased from CellSystems Biotechnologie Vertrieb $\mathrm{GmbH}$ (St. Katharinen, Germany). For experiments, raft models of early maturation stages were used. Reconstructed epidermis was cultured air-lifted on a permeable filter and supplied with maintenance media (Cell Systems Biotechnologie Vertrieb $\mathrm{GmbH}$ ) with or without PV IgG from the basal side only.

After completion of the experiments, samples of both models were processed for immunostaining as described (see Skin Biopsy of Patients with PV and Processing of Cryosections). Parts of the raft cultures were additionally subjected to Laemmli buffer containing $20 \mu \mathrm{g} / \mathrm{mL}$ protease inhibitors aprotenin, leupeptin, and pepstatin (Sigma-Aldrich), and were ground via 10 strokes of a homogenizer. Samples were spun down at $4^{\circ} \mathrm{C}$, and supernatant was frozen at $-80^{\circ} \mathrm{C}$ until use for Western blot analysis, as described elsewhere. ${ }^{22}$

\section{Neonatal Mouse Model}

All animal experiments were approved by the Regierung von Unterfranken (Az 55.2-2531.01-4/10). Neonatal mice aged 1 to 2 days and weighing less than $2 \mathrm{~g}$ were injected intradermally in the skin of the back with $50 \mu \mathrm{L}$ IgG from a healthy volunteer (control IgG, $6 \mathrm{mg} / \mathrm{g}$ body weight) or PV3 IgG (6 mg/g body weight). At 2 hours before receiving the IgG fractions, mice were preinjected with either $50 \mu \mathrm{L}$ PBS, $500 \mathrm{nmol} / \mathrm{L}$ Gö6976, or $40 \mu \mathrm{mol} / \mathrm{L}$ safingol, together with a second dose of the inhibitors. After 20 hours, the mice were sacrificed, and skin samples were collected. Samples were embedded in cryo mounting medium (Reichert-Jung $\mathrm{GmbH}$, Nussloch, Germany) and snap-frozen. The frozen samples were cut using a cryostat (Frigocut 2800; Cambridge Instruments $\mathrm{GmbH}$ ). Every 400 $\mu \mathrm{m}$, one section was stained in $1 \%$ toluidine blue solution and examined for the presence or absence of intraepidermal cleavage until the entire sample was processed. Representative cryosections were subjected to immunostaining as described elsewhere ${ }^{23}$ and to H\&E staining according to standard procedures. A Cy3-labeled goat anti-human antibody (diluted 1:600 in PBS; Dianova $\mathrm{GmbH}$ ) was used to visualize bound PV IgG within the epidermis.

\section{Keratinocyte Dissociation Assay}

Cells were grown in 12-well plates as described, and were incubated for 24 hours with PV IgG with or without Gö6976 or safingol. Cells were washed with HBSS and incubated for 30 minutes with dispase II in HBSS (>2.4 $\mathrm{U} / \mathrm{mL}$; Sigma-Aldrich) to detach the monolayer from the well bottom. The dispase solution was replaced with 500 $\mu \mathrm{L}$ HBSS, and the monolayer was mechanically stressed by pipetting it up and down five times using a 1-mL pipet. Resulting fragments were counted using a binocular microscope at the same magnification.

\section{Electrophoresis and Western Blot Analysis}

Cells were grown in 12-well plates as described. Detection of Dsg3 was performed using Western blot analysis according to standard procedures as described previously. ${ }^{22}$ Primary antibodies used were rabbit polyclonal Dsg3 antibody (clone H-145; 1:1000 dilution; Santa Cruz 
Biotechnology, Inc.), mouse monoclonal Dsg2 antibody (clone 10G11; 1:200 dilution) and mouse monoclonal Dsg1 antibody (clone p124; 1:100 dilution) (both from Progen Biotechnik GmbH, Heidelberg, Germany), and polyclonal rabbit PKC $\alpha$ antibody (1:1000 dilution; New England Biolabs, Frankfurt, Germany). Peroxidase-conjugated goat anti-rabbit and goat anti-mouse antibodies (1:3000 dilution) served as secondary antibodies. Membranes were developed using the ECL System (GE Healthcare Europe GmbH, Freiburg, Germany). Signals were detected using either conventional radiography or a digital chemoluminescence reader (Fluorchem HD2; Cell Biosciences, Inc., Santa Clara, CA).

\section{Cytochemistry}

HaCaT cells and normal human epidermal keratinocytes (NHEK) were grown on coverslips as described previously. Immunostaining was performed as described elsewhere. ${ }^{24} \mathrm{~A}$ monoclonal Dsg3 antibody (clone 5G11; dilution 1:100; Invitrogen $\mathrm{GmbH}$ ) and a goat anti-mouse Cy3-linked secondary antibody (dilution 1:600; Dianova $\mathrm{GmbH}$ ) were used for visualization.

\section{Image Acquisition and Processing}

Immunostained sections and coverslips were imaged using a confocal laser scanning microscope (LSM510) equipped with $63 \times 1.4$ Plan Apochromat (oil), $40 \times N A$ 1.3 Plan NeoFluar (oil), and $20 \times 1.8$ Plan Apochromat objectives (all from Carl Zeiss Microlmaging $\mathrm{GmbH}$, Goettingen, Germany). H\&E-stained sections were photographed using a digital camera (model HRP-100; Diagnostic Instruments, Inc., Sterling Heights, MI) attached to an Axiomot 2 Plus microscope equipped with a Plan NeoFluar $20 \times 0.50$ objective (both from Carl Zeiss Microlmaging $\mathrm{GmbH}$ ). ImageJ software (National Institutes of Health, Bethesda, MD) was used for fluorescence intensity measurements. Figure compilations were performed using Photoshop CS3 and Illustrator CS3 software (Adobe Systems GmbH, München, Germany).

\section{Detection of PKC Activity}

PKC activity was measured using the PepTag nonradioactive PKC assay (Promega $\mathrm{GmbH}$, Mannheim, Germany) based on the different migration behavior of a colored PKC substrate peptide dependent on its phosphorylation state in an electrical field. In brief, after 15 minutes of incubation with PV1 IgG or after 60 minutes of preincubation with $500 \mathrm{nmol} / \mathrm{L}$ Gö6976 or 40 $\mu \mathrm{mol} / \mathrm{L}$ safingol followed by 15 minutes of treatment with PV IgG, HaCaT cells were scraped into lysis buffer $(25 \mathrm{mmol} / \mathrm{L}$ Tris- $\mathrm{HCl}, 0.5 \mathrm{mmol} / \mathrm{L}$ EDTA, $0.5 \mathrm{mmol} / \mathrm{L}$ EGTA, $0.05 \%$ Triton X-100, $10 \mathrm{mmol} / \mathrm{L} \beta$-mercaptoethanol, $1 \mu \mathrm{g} / \mathrm{mL}$ leupeptin, $1 \mu \mathrm{g} / \mathrm{mL}$ aprotinin, and $0.5 \mathrm{mmol} / \mathrm{L}$ phenylmethylsulfonyl fluoride) and incubated with the substrate peptide for 30 minutes, according to the manufacturer's instructions. After stopping the reaction for 10 minutes at $95^{\circ} \mathrm{C}$, solution was applied to a $0.8 \%$ agarose gel. The phosphorylated peptide migrates to the cathode because of its negative net charge, whereas the non-phosphorylated peptide migrates toward the anode. For quantification, the phosphorylated bands were cut out, solubilized using the solubilization buffer provided, and absorption was determined at $570 \mathrm{~nm}$ using a spectrophotometer.

\section{Statistical Analysis}

Data were analyzed using commercially available software (Prism; GraphPad Software, Inc., San Diego, CA). Data for the two groups were compared using the two-tailed Student's t-test. For multiple group comparisons, one way analysis of variance with the Bonferroni post hoc test was used. Statistical significance was assumed at $P<0.05$. Error bars in graphs represent standard error, mean $\pm S D$.

\section{Results}

\section{Dsg3 Depletion in Skin from Patients with PV Is Detectable in Deep Epidermal Layers Only}

We first analyzed whether loss of Dsg3 was detectable in patient skin. Sections of perilesion skin derived from two patients with PV and two healthy volunteers were stained for Dsg3 expression. In controls, Dsg3 was distributed at cell membranes throughout the basal and spinous layers (Figure 1A). In the basal layer, staining was more punctuated, whereas in the spinous layer, Dsg3 was linearly distributed along the cell borders. In PV sections, Dsg3 staining was more disorganized than in controls (Figure 1B). In addition, reduced global staining intensity in the basal cell layers was often detectable, with absence of Dsg3 at the cell borders. To quantify this observation, staining intensity was evaluated according to the following principle throughout several sections of each patient skin tissue sample. The mean fluorescence intensity of an area comprising the basal cell layer, independent of whether a histologically visible blister was present, was divided by the mean fluorescence intensity of the most superficial cell layer positive for Dsg3 staining (Fb/s). This was compared with the ratio of the fluorescence of an intermediate layer of the epidermis divided by the superficial layer $(\mathrm{Fm} / \mathrm{s})$. By building these ratios, differences due to variations in staining efficacy were negligible. Between 9 and 27 areas per specimen, covering approximately $80 \%$ of the total section length, were investigated (Figure 1C). The $\mathrm{Fb} / \mathrm{s}$ of sections from control patient 1 was $0.88 \pm 0.05$, and from control patient 2 was $0.92 \pm 0.04$. The $\mathrm{Fb} / \mathrm{s}$ was significantly reduced in PV patient sections with values of $0.64 \pm$ 0.03 and $0.62 \pm 0.05$, respectively. In contrast, no significant differences were observed in $\mathrm{Fm} / \mathrm{s}$ (Figure 1D; $1.15 \pm 0.04$ and $1.32 \pm 0.04$ in controls versus $1.19 \pm 0.03$ for PV patient 1 and $1.34 \pm 0.08$ for PV patient 2, respectively). To rule out possible masking of epitopes by PV antibodies binding to the same region as the monoclonal Dsg3 antibody used for detection, 

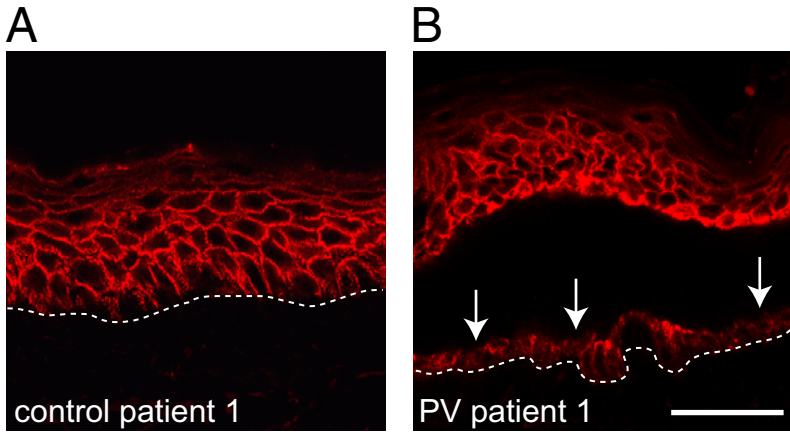

C
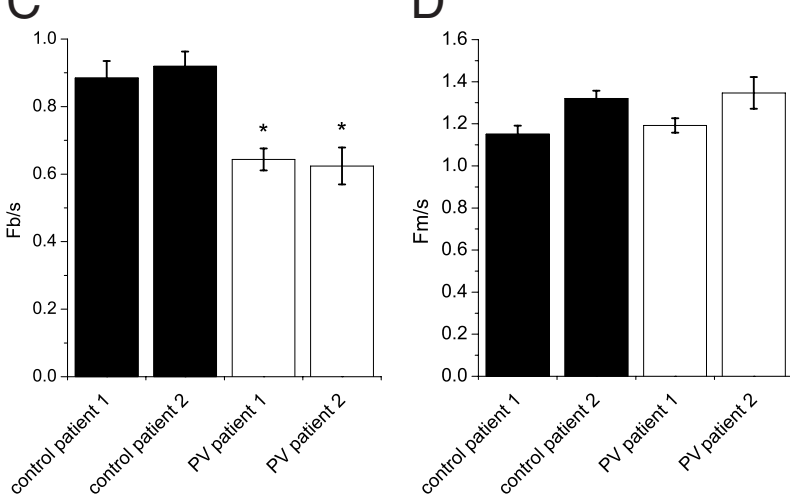

Figure 1. Depletion of Dsg3 occurs predominantly in the deep epiderma layers. Sections from skin biopsy specimens from two healthy volunteers (controls) and two patients with PV were immunostained for Dsg3. A: In controls, Dsg3 was regularly distributed along the cell borders in the basal and spinous layers. B: In sections from patients with PV, Dsg3 was disorganized, and fragmentation and loss of staining intensity were predominantly detectable in the basal layer (arrows). Dashed lines represent the dermalepidermal junction. Staining intensity was measured to quantify these impressions. The most superficial layer with Dsg3 detectable at the cell borders served as the internal reference to exclude artifacts by variations in staining quality. Scale bar $=50 \mu \mathrm{m}$. C: The ratio of staining intensity in the basal layer over staining intensity of superficial layers $(\mathrm{Fb} / \mathrm{s})$ was decreased in biopsy specimens from both patients with PV, indicating depletion of Dsg3 in the basal layer. D: The ratio of intermediate layers over superficial layer $(\mathrm{Fm} / \mathrm{s})$ determined at the same positions as $\mathrm{Fb} / \mathrm{s}$ was similar in specimens from controls and patients with PV ( $n=9$ to 27$)$. ${ }^{*} P<0.05$ versus both control patients.

sections from control patient 1 and PV patient 1 were stained using an antibody directed against the intracellular Dsg3 region (amino acids 855 to 999). Again, staining was specifically reduced in the basal layer (see Supplemental Figure S1 at http://ajp.amjpathol. org). These data indicate that loss of Dsg3 predominantly occurs in the deep epidermal layers.

We sought to support these results via Western blot analysis and detection of Dsg3 in lysates from skin of patients with PV. However, no significant reduction of Dsg3 protein levels was visible in PV patients compared with controls (data not shown). We explain this discrepancy with the immunofluorescence experiments outlined above using the assumption that specific depletion of Dsg3 in the basal layers may be masked by the absence of depletion in the other layers. To prove this hypothesis, we used an organotypic human skin model grown on filter membranes that were incubated with PV IgG. We applied this model in a relatively low state of differentiation ( 7 days after airlift) comprised of only three to four keratinocyte layers and with minor cornification. Under these conditions, incubation with $500 \mu \mathrm{g} / \mathrm{mL}$ PV1 IgG from the basal side of the epidermis for 24 hours induced fragmentation of Dsg3 staining specifically in the basal and suprabasal cell layers, whereas in controls, a more linear distribution was observed (Figure 2, A and B). Blister formation was not detectable, possibly because of the absence of mechanical stress and the low amounts of Dsg1 autoantibodies in the two IgG fractions used. Staining with an antibody directed against the Fc part of human IgG (Figure 2, C and D) demonstrated deposition of PV IgG throughout the reconstituted epidermis, ruling out the possibility that autoantibodies did not diffuse effectively and failed to bind to the more superficial layers. Similar to PV patient skin, incubation with PV1 IgG induced a decrease of basal over superficial fluorescence intensity from $1.57 \pm 0.13$ (controls) to $1.10 \pm$ 0.06 (Figure 2E). Next, Dsg3 levels in these organotypic models were detected using Western blot analysis. Compared with controls, Dsg3 levels were reduced to $70.7 \% \pm 5.9 \%$ after incubation with PV1 IgG (Figure $2 \mathrm{~F})$. Considered together, data from both patient skin and reconstituted epidermis indicated that Dsg3 depletion occurs primarily in the deep epidermal layers.
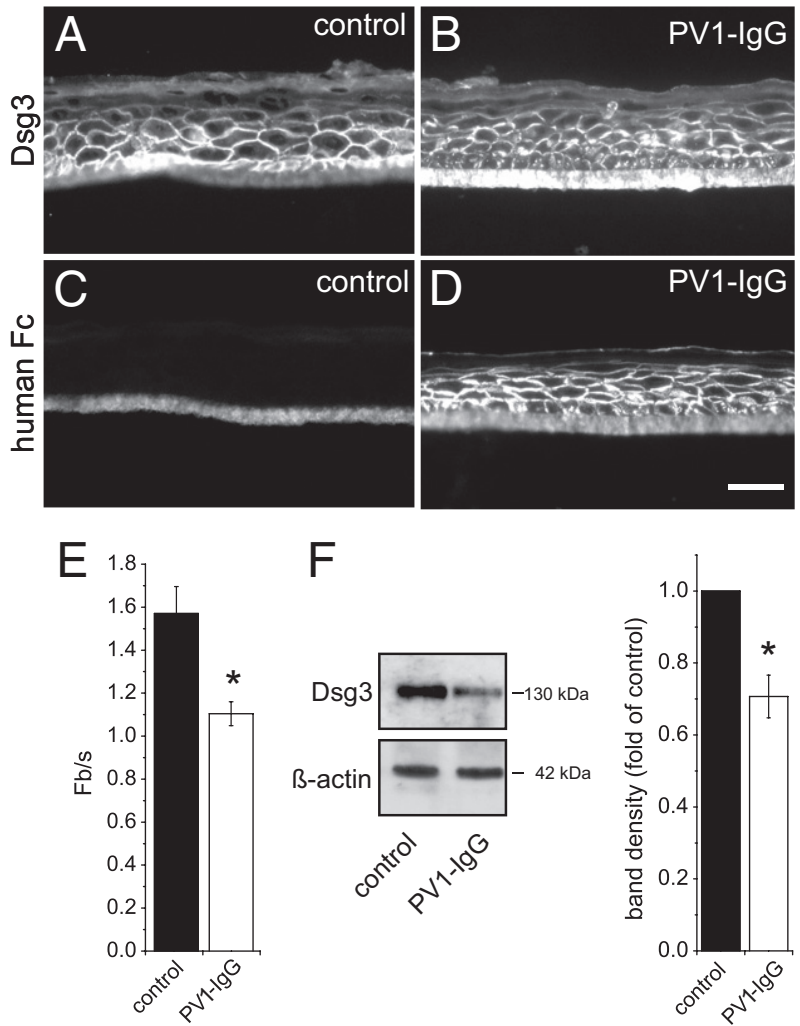

Figure 2. Dsg3 depletion is detectable in the basal layers of reconstituted epidermis after incubation with PV IgG. A and B: Juvenile epidermal raft models were incubated with PV1 IgG and stained for Dsg3. C and D: Reorganization and loss of staining were prominent in the deep epiderma layers only, although PV IgG binding was detectable throughout the epidermis and was not confined to the basal layer only, as demonstrated by staining with an antibody against human Fc. E: Quantification revealed decreased $\mathrm{Fb} / \mathrm{s}(n=7$ to 10$) .{ }^{*} P<0.05$ versus control. Scale bar $=20 \mu \mathrm{m}$. F: Dsg3 levels were reduced after incubation with PV1 IgG as determined using Western blot analysis $(n=6) .{ }^{*} P<0.05$ versus control. 


\section{Dsg3 Depletion Is Prominent in Keratinocytes Exposed for Short Periods to High-Ca ${ }^{2+}$ Medium and Is Dependent on PKC Signaling}

Dsg3 distribution and Dsg3 levels were examined in cultured keratinocytes. Two different cell lines were used in this approach under conditions shown in Figure 3A. The first cell line used was the spontaneously immortalized $\mathrm{HaCaT}$ cell line, which is regularly cultured in medium containing $1.8 \mathrm{mmol} / \mathrm{L} \mathrm{Ca}^{2+}{ }^{25}$ After seeding, cells were maintained in high- $\mathrm{Ca}^{2+}$ medium for 3 days, thereby reaching confluence, before incubation with PV IgG. For comparison, $\mathrm{HaCaT}$ cells were seeded at the same density and were maintained for 8 days in high- $\mathrm{Ca}^{2+}$ medium before PV IgG was added. Finally, NHEKs derived from skin explants were used. These cells were cultured in keratinocyte growth medium containing $0.15 \mathrm{mmol} / \mathrm{L} \mathrm{Ca}^{2+}$ until complete confluence was reached, and then transferred to $1.8 \mathrm{mmol} / \mathrm{L} \mathrm{Ca}^{2+}$ for 24 hours before incubation with $\mathrm{PV} / \mathrm{gG}$ for another 24 hours. The NHEK cells did not tolerate the high- $\mathrm{Ca}^{2+}$ conditions for prolonged times.

In immunostaining experiments, Dsg3 was observed to be linearly localized at cell borders in all controls (Figure 3, B-D). Treatment with PV1 IgG for 24 hours induced an overall decrease in Dsg3 staining, with only some Dsg3positive areas at cell membranes in cells incubated for short periods in high- $\mathrm{Ca}^{2+}$ medium $(\mathrm{HaCaT} 3 \mathrm{~d}$ and NHEK; Figure 3, E and G).

In contrast, the effect of PV1 IgG was drastically reduced when $\mathrm{HaCaT}$ cells grown for 8 days in high- $\mathrm{Ca}^{2+}$ medium were used. Here, Dsg3 staining was fragmented but was still clearly detectable at the cell borders (Figure 3F).

Recently, PKC $\alpha$ signaling has been implicated in a process termed desmosome hyperadhesion, rendering cadherin-mediated adhesion independent of extracellular $\mathrm{Ca}^{2+}$. In addition, PV IgG induces rapid activation of PKC. ${ }^{26,27}$ We used Gö6976, an inhibitor of classic PKC isoforms $\mathrm{PKC} \alpha, \mathrm{PKC} \beta$, and $\mathrm{PKC} \gamma$. Loss of Dsg3 staining was drastically reduced when $\mathrm{HaCaT}$ and NHEK cells cultured for 3 days were co-incubated with Gö6976 (Figure 3, $\mathrm{H}$ and J). Dsg3 appeared in a punctuate pattern at the cell borders and, thus, resembled the outcome of 8-day-cultured $\mathrm{HaCaT}$ cells treated with PV1 IgG. Coincubation of 8-day-cultured HaCaT cells with Gö6976 and PV1 IgG yielded a Dsg3 distribution similar to that with PV1 IgG treatment alone (Figure 3I). Similar results were obtained when another PKC inhibitor, safingol, was used (Figure 3, K-M).

We next determined the effect of PV1 IgG on PKC activity (Figure $3 \mathrm{~N}$ ). In HaCaT cells cultured for 3 days, PKC activity significantly increased 2.9-fold \pm 0 .3-fold compared with controls after 15 minutes of PV1 $\mathrm{lgG}$ incubation. This effect was abrogated by preincubation for 1 hour with the PKC inhibitor Gö6976 (1.39-fold \pm 0.27 -fold of control) and safingol (1.37-fold \pm 0.56 -fold of control), respectively. In HaCaT cells cultured for 8 days, no significant increase in PKC activity was observed under the same conditions (0.76-fold \pm 0.3 -fold of control). Nevertheless, PKC activity was further reduced by Gö6976 (0.42-fold \pm 0.09 -fold of control) and safingol (0.57-fold \pm 0.06 -fold of
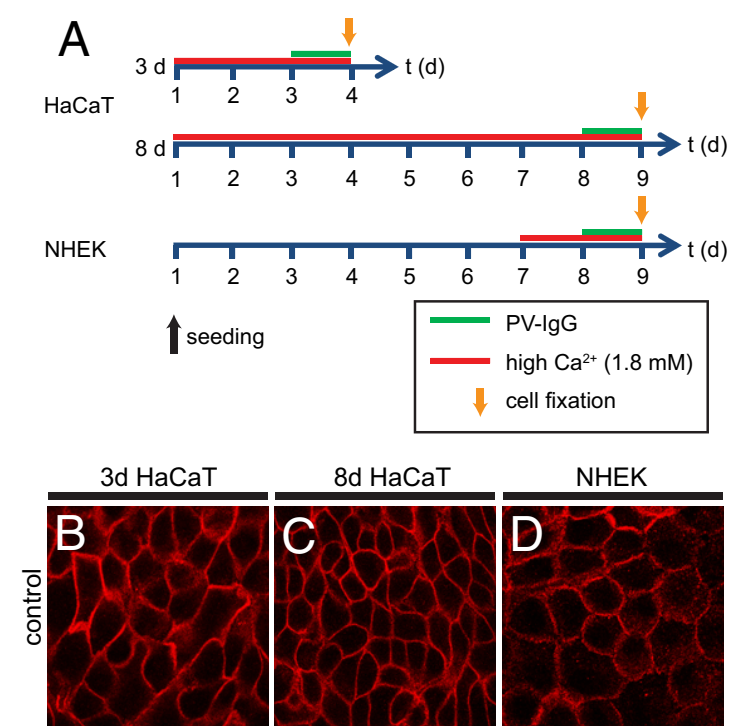

$8 \mathrm{~d} \mathrm{HaCaT}$

NHEK
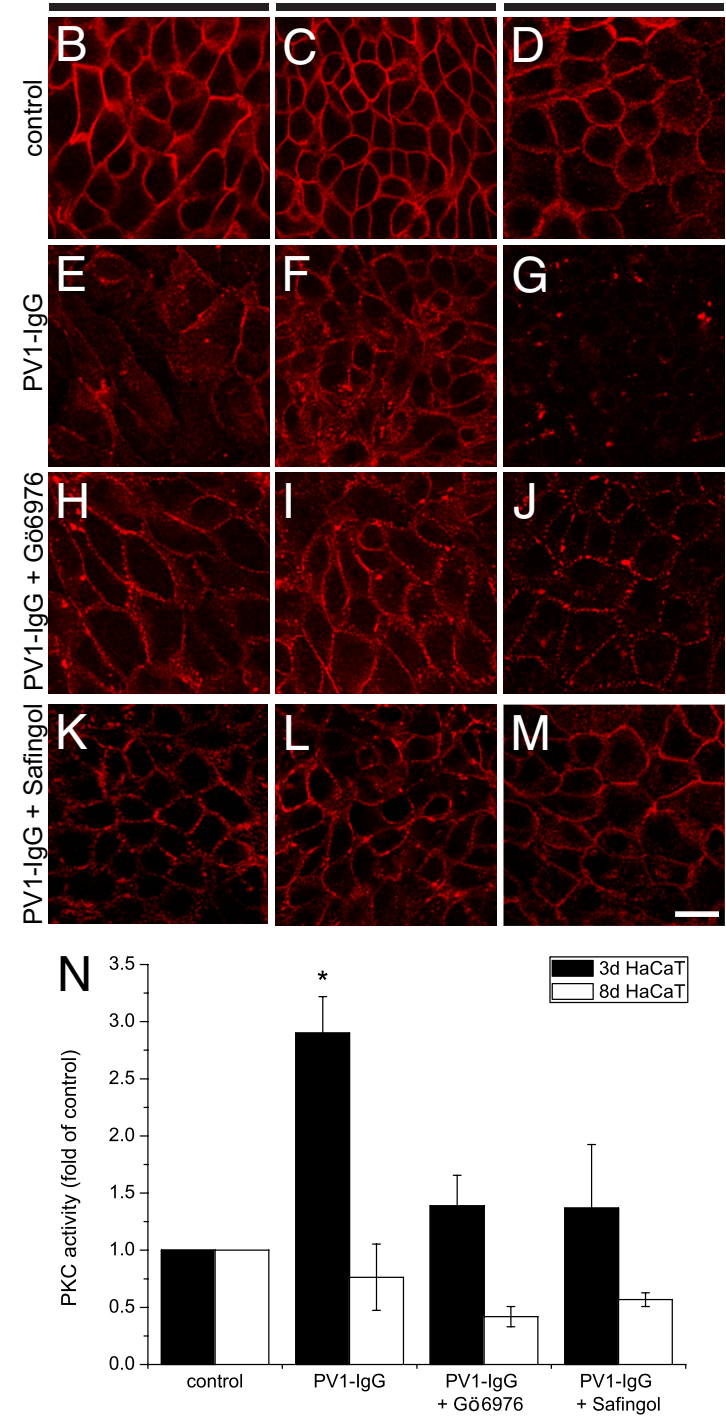

Figure 3. Dsg3 depletion and reorganization in cultured keratinocytes are dependent on incubation time in high- $\mathrm{Ca}^{2+}$ medium and PKC signaling. A: Schema of the conditions used in keratinocyte cultures and experiments. B-D: Dso3 staining was cultured for 8 days. Loss of Dsg3 staining after incubation with PV1 IgG was most prominent in HaCaT cells cultured for 3 days and NHEK cells $(\mathbf{E}$ and $\mathbf{G})$, whereas staining was only fragmented but not globally reduced in HaCaT cells cultured for 8 days (F). Simultaneous inhibition of PKC by Gö6976 (H and J) or safingol (K and $\mathbf{M})$ reduced prominent loss of Dsg3 staining in HaCaT cells cultured for 3 days and NHEK cells, but had minor effects on HaCaT cells cultured for 8 days $(\mathbf{I}$ and $\mathbf{L}$ ). Representative data from four independent experiments are shown. Scale bar $=20$ $\mu \mathrm{m}$. N: PKC activity is increased in HaCaT cells cultured for 3 days but not in HaCaT cells cultured for 8 days. Preincubation with Gö6976 or safingol for 1 hour reduced the amount of active PKC compared with PV1 IgG treatment alone (HaCaT cells cultured for 3 days) or controls (HaCaT cells cultured for 8 days) $(n=4) .{ }^{*} P<0.05$ versus control. 
A

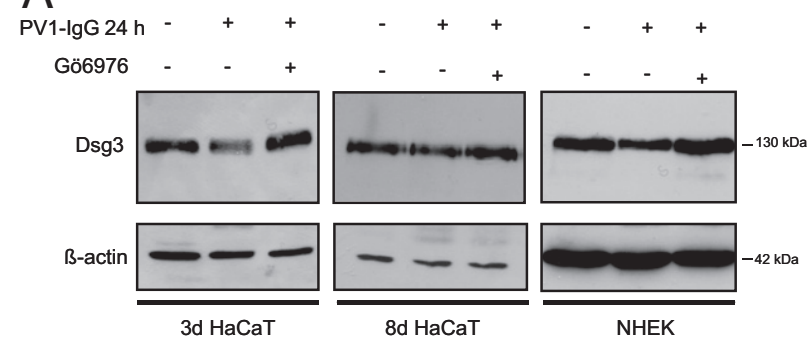

B

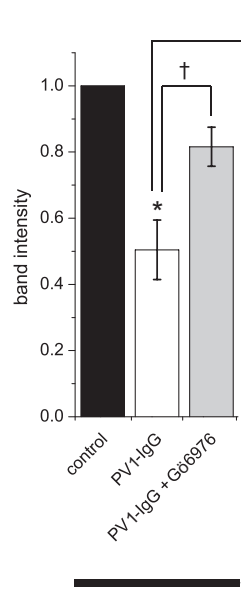

$\ddagger$
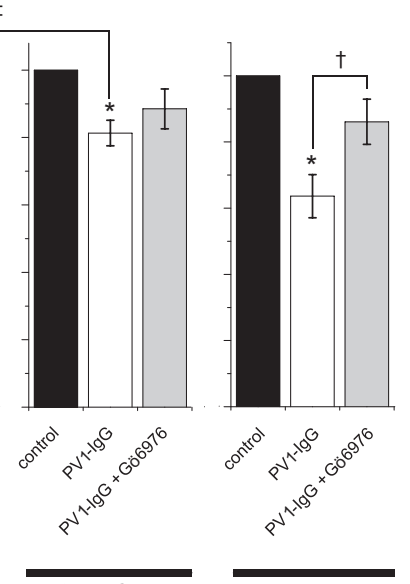

3d HaCaT

8d HaCaT

NHEK

C

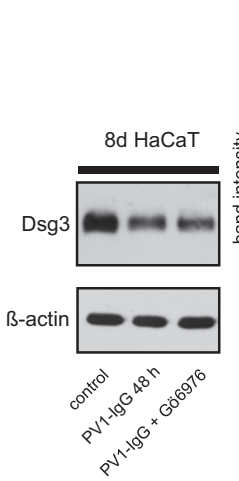

D

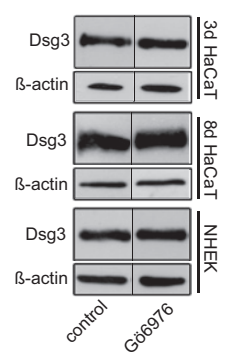

Figure 4. Depletion of cellular Dsg3 levels in response to PV IgG treatment is modified by PKC signaling in HaCaT cells cultured for 3 days and NHEK cells. Dsg3 levels of cultured keratinocytes used under the same conditions as depicted in Figure 3A were detected using Western blot analysis. A: Depletion after PV1 IgG incubation was prominent in HaCaT cells cultured for 3 days and NHEK cells but was less pronounced in HaCaT cells cultured for 8 days. Consistent with Figure 3, effects were blocked by co-incubation with Gö6976. B: Results of densitometry. C: Prolonged ( 48 hours) incubation with PV1 IgG led to increased depletion in HaCaT cells cultured for 8 days, which was not blocked by Gö6976. D: Incubation with Gö6976 alone for 24 hours had no effect on Dsg3 levels $(n=>5) . P<0.05$. ${ }^{* P V 1-I g G ~ v e r s u s ~}$ respective control; ' $\mathrm{PV} 1 \mathrm{IgG}$ versus PV1-IgG + Gö6976; 'PV1-IgG of HaCaT cells cultured for 3 days versus PV1 IgG of HaCaT cells cultured for 8 days (not significant).

control). Thus, PKC activity correlated inversely with Dsg3 depletion observed in immunostaining experiments.

In the next set of experiments, Dsg3 levels were quantified under the conditions delineated in Figure 3A. Western blot analysis of Dsg3 levels revealed a prominent reduction in cells maintained for short periods in high$\mathrm{Ca}^{2+}$ medium (Figure 4, A and B). Compared with controls, 24-hour incubation with PV1 IgG significantly decreased the amount of Dsg3 in 3-day-cultured $\mathrm{HaCaT}$

cells to $50.4 \% \pm 9.0 \%$, and in NHEK cells to $63.6 \% \pm$ $6.5 \%$, respectively $(n>5)(P<0.05)$. Dsg3 depletion in $\mathrm{HaCaT}$ cells cultured for 8 days $(81.3 \% \pm 3.8 \%)$ was significantly less than in $\mathrm{HaCaT}$ cells cultured for 3 days. Consistent with data from immunofluorescence studies, co-incubation with Gö6976 significantly reduced Dsg3 depletion in 3-day-cultured HaCaT and NHEK cells to $81.6 \% \pm 5.9 \%$ and $86.1 \% \pm 6.8 \%$, respectively. In HaCaT cells cultured for 8 days, Dsg3 levels were not different $(88.5 \% \pm 5.9 \%)$ from those after PV1 IgG treatment alone. Experiments using PV2 IgG yielded similar results. When HaCaT cells cultured for 8 days were incubated with PV1 IgG for 48 hours rather than 24 hours (Figure 4C), more prominent Dsg3 depletion was detectable $(40.3 \% \pm 9 \%$ compared with controls). However, in contrast to 3-day-cultured HaCaT and NHEK cells, PKC inhibition by Gö6976 did not significantly reduce the effect of PV1 lgG (53.2\% $\pm 10 \%$ compared with controls). Incubation with Gö6976 alone had no effect on Dsg3 protein levels in HaCaT or NHEK cells (Figure 4D).

Because PKC $\alpha$ is the only classic isoform expressed in keratinocytes, ${ }^{28}$ it may be concluded that this is the only classic PKC isoform inhibited by Gö6976. In addition, safingol specifically targets the regulatory domain of PKC $\alpha .{ }^{29}$ However, small-interfering RNA-mediated knockdown in HaCaT cells cultured for 3 days (see Supplemental Figure S2 at http://ajp.amjpathol.org) did not prevent Dsg3 depletion in response to PV1 IgG and PV2 IgG (data not shown) compared with control transfected cells.

Considered together, the data demonstrate that Dsg3 depletion and reorganization in response to PV IgG were dependent on culture conditions and were most prominent in cells exposed to regular $\mathrm{Ca}^{2+}$ concentrations for short periods. Moreover, these effects were ameliorated by pharmacologic inhibition of PKC signaling.

\section{Loss of Keratinocyte Adhesion Is Blunted by PKC Inhibition in 3d HaCaT and NHEK}

To investigate whether Dsg3 depletion is also functionally relevant, we performed keratinocyte dissociation assays. A confluent monolayer was released from the well bottom via digestion with dispase II and exposed to mechanical stress. The number of resulting fragments is a measure of loss of intercellular adhesion. Under all conditions, fragment numbers in controls were less than 10 per well of a 12-well plate. Compared with controls, incubation with PV1 IgG increased the number of fragments by 28.8-fold \pm 0.8-fold ( $\mathrm{HaCaT}$ cells cultured for 3 days; Figure 5A), 28.9-fold \pm 4.7-fold ( $\mathrm{HaCaT}$ cells cultured for 8 days; Figure 5B), and 78.0-fold \pm 14.5-fold (NHEK cells, Figure 5C), respectively. In HaCaT cells cultured for 3 days, co-incubation of PV1 IgG with Gö6976 or of PV1 IgG with safingol significantly blocked fragmentation (21.9-fold \pm 2.5-fold and 19.6-fold \pm 3.5-fold, respectively, compared with controls), whereas in $\mathrm{HaCaT}$ cells cultured for 8 days, no protective effect was detectable (37.6-fold \pm 6.6-fold and 32.4-fold \pm 5.8-fold, respectively, compared with controls). Consistent with the idea that depletion contributes to loss of cell adhesion primar- 


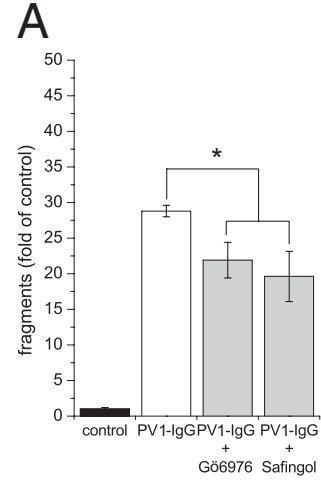

3d $\mathrm{HaCaT}$

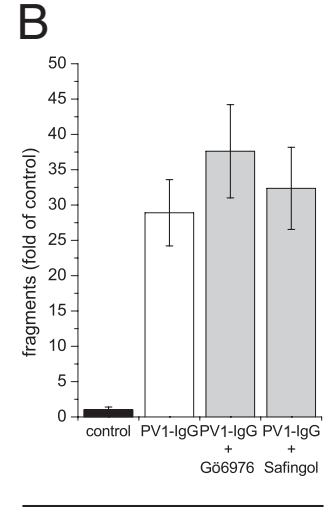

8d HaCaT

\section{C}

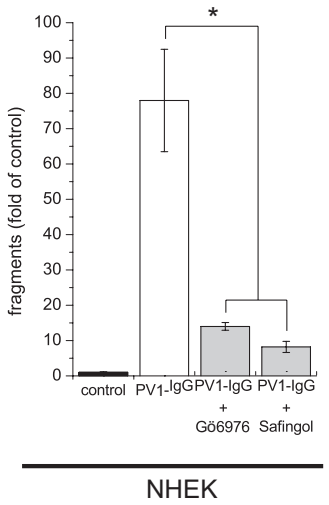

Figure 5. Loss of cell adhesion is blunted by PKC inhibition in HaCaT cells cultured for 3 days and NHEK cells. Dispasebased keratinocyte dissociation assays were performed to quantify loss of cell adhesion. Treatment with PV1-IgG for 24 hours induced strong fragmentation under all conditions. Simultaneous treatment with Gö6976 or safingol blunted cell dissociation in $\mathrm{HaCaT}$ cells cultured for 3 days (A) and in NHEK cells $(\mathbf{C})$ but was ineffective in HaCaT cells cultured for 8 days $(\mathbf{B})(n=>6)$. ${ }^{*} P<0.05$ versus PV1 IgG-treated group. ily in cells maintained for short periods in high- $\mathrm{Ca}^{2+}$ medium, co-treatment of NHEK cells with Gö6976 or safingol both abrogated cell sheet fragmentation (14-fold \pm 1.1 fold and 8.2-fold \pm 1.6-fold, respectively, compared with controls). Similar to the depletion experiments, in dissociation assays, PKC $\alpha$ knockdown did not reduce the number of fragments induced by PV1 IgG (see Supplemental Figure S2C at http://ajp.amjpathol.org) or PV2 IgG (data not shown) compared with control transfection. Nevertheless, it can be concluded that pharmacologic PKC inhibition decreased loss of cell adhesion of PV IgG only under conditions in which prominent Dsg3 depletion was present.

\section{PKC Inhibition Does Not Protect Against PV IgG-Induced Dsg3 Depletion by Up-Regulation of Dsg1 and Dsg2}

We evaluated protein expression levels of Dsg1 and Dsg2 to determine whether other desmoglein isoforms were affected by PV IgG and PKC inhibition. In young HaCaT cultured cells, Dsg1 protein is typically not detectable; however, Dsg1 is present in HaCaT cells cultured for 8 days in high-Ca2 ${ }^{+}$medium (Figure 6A). In contrast, Dsg1 was clearly detectable in NHEK cells exposed to high- $\mathrm{Ca}^{2+}$ concentrations for 24 hours (Figure $6 \mathrm{~B})$, and Dsg1 levels remained stable after 24 hours of incubation with Gö6976. Under conditions of strong Dsg3 depletion (Figure 6C), Dsg1 levels remained unchanged after incubation with PV1 IgG (Dsg3 autoantibodies only) or PV2 IgG (Dsg3 and Dsg1 autoantibodies) alone or in combination with Gö6976. In contrast to NHEK cells, which express no or low amounts of Dsg2 only ${ }^{30,31}$ (Figure 6D), Dsg2 is stably present in HaCaT cells (see Supplemental Figure S3 at http://ajp.amjpathol.org). Similar to the situation with Dsg1 in NHEK cells, PV1 IgG did not induce profound alterations in Dsg2 levels in HaCaT cells cultured for 3 days (Figure 6E) or 8 days (Figure 6F). Dsg2 levels were also unchanged in combination with Gö6976. Similar results were obtained for PV2 IgG (data not shown). According to these data, it is unlikely that PKC inhibition blocked PV IgG-induced Dsg3 depletion via up-regulation of Dsg1 and Dsg2.
PKC Inhibition Prevents Dsg3 Depletion in an ex Vivo Model of Human Skin and Blocks Blister Formation in Neonatal Mice

To investigate the effect of PKC inhibition within the epidermis, an ex vivo human skin model was used. ${ }^{7}$ Skin biopsy specimens were incubated with PV1 IgG in the presence or absence of Gö6976. Fragmentation in re-
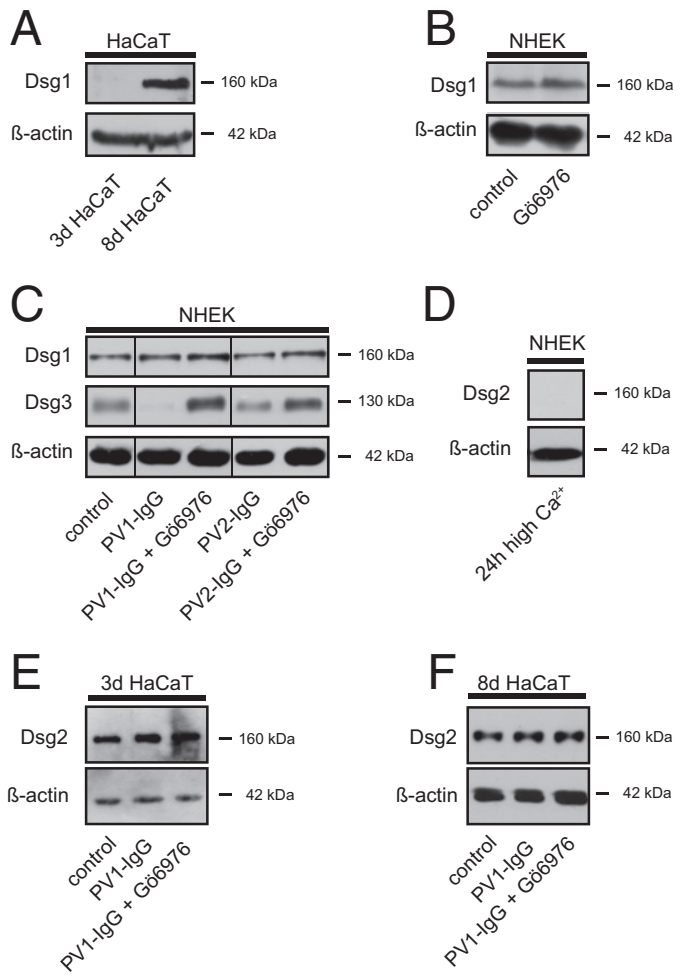

Figure 6. Gö6976 does not induce up-regulation of Dsg1 and Dsg2. A: Dsg is absent in $\mathrm{HaCaT}$ cells cultured for 3 days but is present after culture for 8 days. B: In NHEK cells, Dsg1 is detectable after 24 hours of incubation with $1.8 \mathrm{mmol} / \mathrm{L} \mathrm{Ca}^{2+}$; however, levels are unchanged after 24 hours of incubation with Gö6976. C: Under conditions of Dsg3 depletion, Dsg1 levels remained unaffected by both PV1 IgG and PV2 IgG and by the respective combinations with Gö6976. D: Dsg2 is not detectable in NHEK cells. Similarly to Dsg1 in NHEK cells, in HaCaT cells, Dsg2 levels remained unaffected by PV1 IgG incubation and co-treatment with PV1 IgG and Gö6976 in both HaCaT cells cultured for 3 days $(\mathbf{E})$ and 8 days $(\mathbf{F})(n=3)$ 
sponse to PV1 IgG was observed in the deep epidermal layers only, similar to the experiments with patient biopsy specimens and the epidermal raft models (Figure 7A). This effect was absent after co-incubation with Gö6976. Image analysis (Figure 7B) of several sections of each specimen revealed significant PV1 IgG-induced Dsg3 depletion in the basal layers, as demonstrated by a reduction in $\mathrm{Fb} / \mathrm{s}$ to $0.86 \pm 0.03$ (control, $1.03 \pm 0.03$ ). $\mathrm{Fb} / \mathrm{s}$ was restored by co-treatment with Gö6976 (1.13 \pm 0.05$)$. Incubation with PV2 IgG induced similar effects (data not shown).

To evaluate whether blockage of Dsg3 depletion by PKC inhibition is protective in vivo, a pemphigus mouse model was used. ${ }^{9,32}$ We used another PV IgG fraction, $P V 3$ IgG, which is effective in inducing strong blistering in mice. We first confirmed using Western blot analysis and dissociation assays of $\mathrm{HaCaT}$ cells cultured for 3 and 8 days, and the ex vivo human skin model, that PV3 IgG yielded results similar to those of the other IgG fractions (see Supplemental Figure S4 at http://ajp.amjpathol.org). Neonatal mice were injected intradermally with either control IgG from a healthy volunteer or PV3 IgG at 24 hours after birth. Another group of animals was preinjected with $500 \mathrm{nmol} / \mathrm{L}$ Gö6976 or $40 \mu \mathrm{m}$ safingol at 2 hours before administration of another dose of these inhibitors in combination with PV3 IgG. None of the seven control IgG-injected animals developed erosions, whereas macroscopic and/or histologic blisters were evident in six of eight animals injected with PV 3 IgG (Figure $7 \mathrm{C}$, left panels). In contrast, none of the five animals preinjected with Gö6976 developed histologic blistering. Similarly, none of the 8 safingol-injected animals demonstrated evidence of intraepidermal erosions. Epidermal deposition of injected IgG was present after injection of PV IgG, but was absent after injection of control IgG (Figure 7C, right panels). These data demonstrate that Dsg3 depletion in the basal layers of human epidermis was blocked by PKC inhibition. Moreover, both Gö6976 and safingol prevented blister formation in vivo, indicating a role for Dsg3 depletion in deep epidermal splitting.

\section{Discussion}

The present study demonstrated that depletion is dependent on the culture conditions of human keratinocytes. Depletion was most prominent in cells cultured for short periods in high- $\mathrm{Ca}^{2+}$ medium, and was less prominent when cells were maintained in high- $\mathrm{Ca}^{2+}$ medium for longer periods. This $\mathrm{Ca}^{2+}$-induced susceptibility to $\mathrm{Dsg} 3$ depletion was moderated by PKC signaling because PKC inhibition blocked Dsg3 depletion in response to PV IgG. Consistent with the idea that less differentiated cells are more susceptible to Dsg3 depletion, we demonstrated that in perilesion skin from patients with PV, organotypic epidermis models, and an ex vivo model of human skin, predominantly the basal (eg, less differentiated) keratinocyte layers are affected by depletion. Suprabasal blistering in a mouse model of pemphigus was blocked by PKC inhibition, indicating a contribution of Dsg3 depletion to deep epidermal blistering in PV.
A

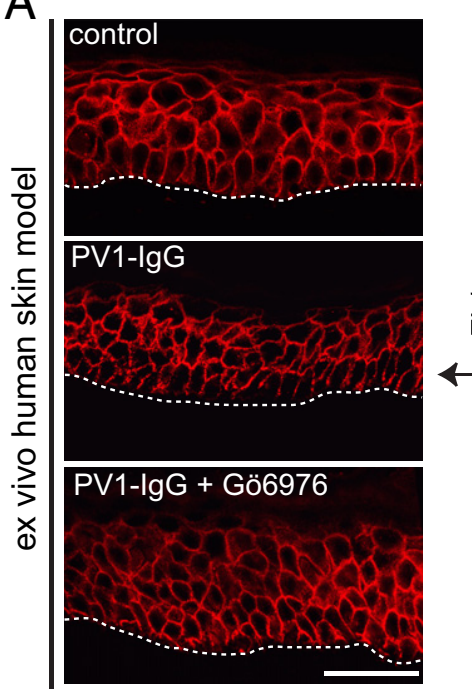

B

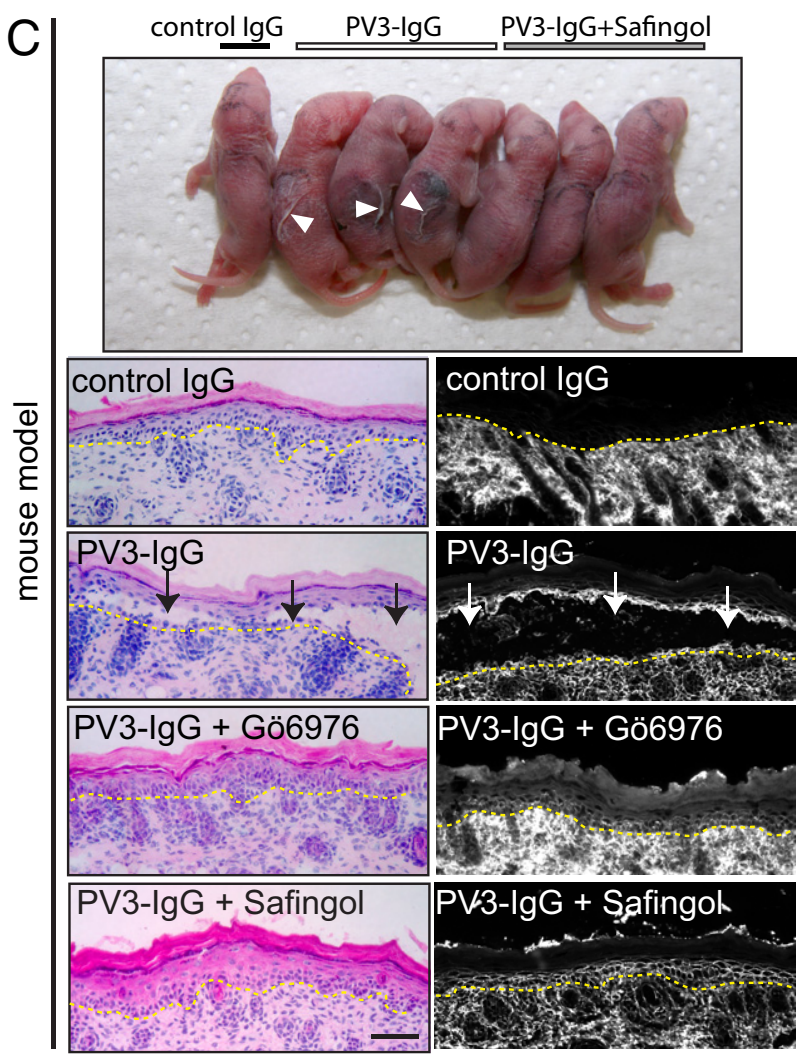

Figure 7. PKC inhibition prevents basal Dsg3 depletion in human epidermis and blister formation in an in vivo mouse model. Human skin biopsy specimens were incubated with PV IgG in the presence or absence of Gö6976, and were snap-frozen. A: Sections were stained for Dsg3. Compared with controls, PV1 IgG induced fragmentation in the deep epidermis (arrow), which was prevented by co-incubation with Gö6976. Scale bar $=50 \mu \mathrm{m}$. B Quantification demonstrated reduction of $\mathrm{Fb} / \mathrm{s}$ in response to PV IgG treatment, which was inhibited by Gö6976 ( $n=22$ to 30$)$. ${ }^{*} P<0.05$ versus controls. C: A neonatal mouse model was used to investigate the efficacy of Gö6976 to block blister formation by PV IgG in vivo. Animals injected with control IgG demonstrated normal skin histologic features as visualized at H\&E staining $(n=7)$, whereas injection of PV3 IgG induced suprabasal blister formation in six of eight animals (upper and left panels). Arrowheads depict macroscopic blisters; arrows indicate intraepidermal cleavage formation. In contrast, none of five animals preinjected with Gö6976 and none of eight animals preinjected with safingol developed blisters. C: IgG deposition was detectable via staining with anti-human Fc antibody after injection of PV3 IgG or combinations with inhibitors but was absent in control IgG-injected animals (right panels). Scale bar $=100 \mu \mathrm{m}$. 


\section{Dsg3 Depletion Is Not Essential for Pathogenic Effects of PV IgG in Vitro and Is Dependent on Cell Culture Conditions}

Dsg3 internalization and depletion have been convincingly demonstrated to occur in response to PV IgG. In HaCaT cells, which we and others used, ${ }^{33,34}$ depletion was not observed when cells were maintained for 5 to 8 days in high- $\mathrm{Ca}^{2+}$ medium. ${ }^{14,24}$ However, typical effects of PV IgG such as Dsg reorganization, intercellular gap formation, and keratin retraction were clearly detectable. ${ }^{14}$ In a recent study, ${ }^{24}$ fragmentation of Dsg3 immunostaining and loss of cell adhesion were detected as soon as 15 minutes after addition of PV IgG, whereas Dsg3 levels remained stable at least throughout the next 6 hours. Moreover, signaling events such as p38MAPK activation in response to PV IgG are similarly evident in $\mathrm{HaCaT}$ cells ${ }^{23}$ and in other cell lines such as primary human keratinocytes, in which we and others ${ }^{17,21}$ have detected Dsg3 depletion. This indicates that Dsg3 depletion is not essential for loss of intercellular adhesion but may under certain conditions contribute to PV pathogenesis.

According to our data, depletion is most prominent in less $\mathrm{Ca}^{2+}$-differentiated cells. In line with this, an interesting concept termed "desmosome hyperadhesion" was recently proposed for keratinocytes. ${ }^{35-37}$ Desmosomal adhesion and desmoglein membrane localization were not impaired further after removal of extracellular $\mathrm{Ca}^{2+}$ when $\mathrm{HaCaT}$ cells were cultured for long periods in high- $\mathrm{Ca}^{2+}$ medium. This was explained by adoption of an ordered arrangement of the desmosomal complex, rendering it insensitive to adhesion-impairing stimuli. ${ }^{38}$ It is likely that this or a similar mechanism slows Dsg3 depletion in 8-day-cultured HaCaT cells after treatment with PV IgG. These data show that certain mechanisms implicated in PV pathogenesis change with the keratinocyte maturation state.

\section{PKC Signaling Renders Keratinocytes Susceptible to Dsg3 Depletion Induced by $P V \lg G$}

Important pathways in keratinocyte differentiation involve PKC signaling. Regarding cell adhesion receptors, expression of Dsg isoforms is regulated by $\mathrm{PKC}{ }^{39}$ In addition, desmosomal hyperadhesion is promoted by inhibition of the PKC $\alpha$ isoform. ${ }^{36,37}$ In the present study, Dsg3 depletion was prevented by inhibition of PKC with Gö6976 in HaCaT and NHEK cells cultured for 3 days. When incubated twice as long (48 hours) with PV IgG, Dsg3 depletion became apparent in $\mathrm{HaCaT}$ cells cultured for 8 days, and Gö6976 was not effective in preventing this loss of Dsg3. This may reflect that PKC activity was not enhanced by PV IgG incubation in HaCaT cells cultured for 8 days. That Dsg3 depletion occurs late in cells cultured for 8 days but readily in cells cultured for 3 days supports the belief that hyperadhesive desmosomes are less prone to depletion. In line with this hypothesis, we did not detect up-regulation of Dsg1 and Dsg3 in response to Gö6976 as underlying mechanism of the protective effect. Rather, Gö6976 may promote induction of hyperadhesive desmosomes.

PKC has earlier been linked to PV pathogenesis. Similar to our study, it has been demonstrated that PV IgG activated $\mathrm{PKC}^{27}$ and that inhibition of PKC blocked skin blistering in vivo. ${ }^{40}$ This is in line with another recent study that demonstrated that desmosome hyperadhesion in response to PKC inhibition prevented pathogenic effects of $\mathrm{PV}$ IgG in vitro. ${ }^{41}$ Consistently, PKC activation has been implicated in disruption of cadherin-mediated junctions in epithelial cells and promotion of invasive behavior. ${ }^{42,43}$ In contrast, PKC activity is important for desmosome assembly. ${ }^{44}$ It is tempting to speculate whether PKC signaling is necessary for dynamic remodeling of desmosomes, which then are more easily destabilized by challenging factors such as $\mathrm{Ca}^{2+}$ depletion or PV IgG treatment. ${ }^{45}$ In this setting, inhibition of PKC may lead to mature desmosomes that are less susceptible to destabilization by internalization and depletion of specific components.

\section{Depletion Predominantly in Basal Epidermal Layers May Contribute to the Cleavage Plane in PV}

The distinct cleavage plane observed in PV and PF was explained by the desmoglein compensation theory, which is based on the hypothesis that autoantibody-induced direct inhibition of Dsg3 and Dsg1 binding is the primary mechanism underlying skin blistering in pemphigus. ${ }^{1,4}$ However, at least in PV, this model has limitations because it does not explain why the split formation is strictly suprabasal. Since both Dsg3 and Dsg1 are expressed throughout the basal and spinous layers ${ }^{3,22}$ cleavage formation should, therefore, occur throughout these layers and not be restricted to the region directly above the basal layer.

In addition, environment-dependent and, thus, epidermal layer-specific mechanisms also may have to be considered. In this context, it is important that an extracellular $\mathrm{Ca}^{2+}$ gradient is detectable in the epidermis, with the highest levels in the granular layer and the lowest levels in the basal layer (450 mg/kg versus $180 \mathrm{mg} / \mathrm{kg}$ ). ${ }^{46-48}$ Because cadherin-mediated adhesion is dependent on $\mathrm{Ca}^{2+}$, it may be speculated that desmoglein binding is stronger in general in the superficial epidermis. However, this is not supported by data from cell-free experiments, which demonstrated, at least for Dsg1, a maximal binding probability at $\mathrm{Ca}^{2+}$ levels of $1 \mathrm{mmol} / \mathrm{L}$. ${ }^{49}$ This corresponds to $40 \mathrm{mg} / \mathrm{kg}$, which is much lower than the values determined for the basal layer.

However, it has been proposed that a hyperadhesive state with fully matured desmosomes is acquired over time in a $\mathrm{Ca}^{2+}$-rich environment. ${ }^{50}$ Thus, it is likely that the superficial epidermal layers are predominantly composed of keratinocytes, with comparatively less dynamic desmosomes. In contrast, the rather low $\mathrm{Ca}^{2+}$ levels within the basal layer would favor increased desmosomal component turnover, which may be supported by PKC signaling. Compared with superficial cells, keratinocytes 
from deep epidermal layers may be more susceptible to Dsg3 depletion in response to PV IgG.

In addition, $\mathrm{Ca}^{2+}$ is necessary for induction of differentiation and intercellular contact formation within the epidermis. ${ }^{45,51-53}$ Therefore, differentiation-dependent occurrence of mechanisms induced by PV IgG within keratinocytes, which act in addition to direct inhibition of Dsg transinteraction, may participate in deep epidermal blistering. Because of its prominence in the deep epidermal layers, it is possible that Dsg3 depletion contributes to the typical cleavage plane in PV. This is supported by our data that demonstrate that depletion in the basal layers was blocked by Gö6976 in cultured epidermis and that Gö6976, similar to safingol, inhibited blister formation in an in vivo mouse model of pemphigus.

Nevertheless, keratinocyte maturation may also be relevant for other pathways implicated in PV pathogenesis such as epidermal growth factor receptor signaling, which is known to be predominately relevant in the deep epidermal layers. ${ }^{54}$ Similar to PKC-mediated depletion in the present study, epidermal growth factor receptor activation in response to $\mathrm{PV} \lg \mathrm{G}$ was observed to be absent in keratinocytes cultured for longer periods in high- $\mathrm{Ca}^{2+}$ medium. ${ }^{13}$ The concept that keratinocyte maturation may influence the response to PV IgG and facilitate differences in signaling may help to dissolve the conflicting data, and requires further elucidation.

\section{Acknowledgments}

We thank Gregory S. Harms for help with imaging, and Lisa Bergauer, Tetjana Frantzeskakis, and Veronica Heimbach for technical assistance.

\section{References}

1. Stanley JR, Amagai M: Pemphigus, bullous impetigo, and the staphylococcal scalded-skin syndrome. N Engl J Med 2006, 355:18001810

2. Waschke J: The desmosome and pemphigus. Histochem Cell Biol 2008, 130:21-54

3. Mahoney MG, Hu Y, Brennan D, Bazzi H, Christiano AM, Wahl JK III: Delineation of diversified desmoglein distribution in stratified squamous epithelia: implications in diseases. Exp Dermatol 2006, 15:101-109

4. Mahoney MG, Wang Z, Rothenberger K, Koch PJ, Amagai M, Stanley JR: Explanations for the clinical and microscopic localization of lesions in pemphigus foliaceus and vulgaris. J Clin Invest 1999, 103: 461-468

5. Heupel WM, Zillikens D, Drenckhahn D, Waschke J: Pemphigus vulgaris IgG directly inhibits desmoglein 3-mediated transinteraction. $\mathrm{J}$ Immunol 2008, 181:1825-1834

6. Waschke J, Bruggeman P, Baumgartner W, Zillikens D, Drenckhahn D: Pemphigus foliaceus IgG causes dissociation of desmoglein 1-containing junctions without blocking desmoglein 1 transinteraction. $J$ Clin Invest 2005, 115:3157-3165

7. Spindler V, Drenckhahn D, Zillikens D, Waschke J: Pemphigus IgG causes skin splitting in the presence of both desmoglein 1 and desmoglein 3. Am J Pathol 2007, 171:906-916

8. Berkowitz P, Hu P, Liu Z, Diaz LA, Enghild JJ, Chua MP, Rubenstein DS: Desmosome signaling: inhibition of p38MAPK prevents pemphigus vulgaris IgG-induced cytoskeleton reorganization. J Biol Chem 2005, 280:23778-23784

9. Berkowitz P, Hu P, Warren S, Liu Z, Diaz LA, Rubenstein DS: p38MAPK inhibition prevents disease in pemphigus vulgaris mice. Proc Natl Acad Sci USA 2006, 103:12855-12860
10. Chernyavsky Al, Arredondo J, Kitajima Y, Sato-Nagai M, Grando SA: Desmoglein versus non-desmoglein signaling in pemphigus acantholysis: characterization of novel signaling pathways downstream of pemphigus vulgaris antigens. J Biol Chem 2007, 282: 13804-13812

11. Pretel M, España A, Marquina M, Beatriz Pelacho, López-Picazo J, López-Zabalza J: An imbalance in Akt/mTOR is involved in the apoptotic and acantholytic processes in a mouse model of pemphigus vulgaris. Exp Dermatol 2009, 18:771-780

12. Schmidt E, Gutberlet J, Siegmund D, Berg D, Wajant H, Waschke J: Apoptosis is not required for acantholysis in pemphigus vulgaris. Am J Physiol Cell Physiol 2009, 296:C162-C172

13. Heupel W-M, Engerer P, Schmidt E, Waschke J: Pemphigus vulgaris IgG causes loss of desmoglein-mediated adhesion and keratinocyte dissociation independent of epidermal growth factor receptor. Am J Pathol 2009, 174:475-485

14. Waschke J, Spindler V, Bruggeman P, Zillikens D, Schmidt G, Drenckhahn D: Inhibition of Rho A activity causes pemphigus skin blistering. J Cell Biol 2006, 175:721-727

15. Caldelari R, de Bruin A, Baumann D, Suter MM, Bierkamp C, Balmer V, Muller $\mathrm{E}$ : A central role for the armadillo protein plakoglobin in the autoimmune disease pemphigus vulgaris. J Cell Biol 2001, 153:823-834

16. Aoyama Y, Kitajima Y: Pemphigus vulgaris-IgG causes a rapid depletion of desmoglein 3 (Dsg3) from the Triton X-100 soluble pools, leading to the formation of Dsg3-depleted desmosomes in a human squamous carcinoma cell line, DJM-1 cells. J Invest Dermatol 1999, 112:67-71

17. Yamamoto $Y$, Aoyama $Y$, Shu E, Tsunoda $K$, Amagai M, Kitajima $Y$ : Anti-desmoglein 3 (Dsg3) monoclonal antibodies deplete desmosomes of Dsg3 and differ in their Dsg3-depleting activities related to pathogenicity. J Biol Chem 2007, 282:17866-17876

18. Shu E, Yamamoto Y, Aoyama Y, Kitajima Y: Intraperitoneal injection of pemphigus vulgaris-lgG into mouse depletes epidermal keratinocytes of desmoglein 3 associated with generation of acantholysis. Arch Derm Res 2007, 299:165-167

19. Calkins CC, Setzer SV, Jennings JM, Summers S, Tsunoda K, Amaga M, Kowalczyk AP: Desmoglein endocytosis and desmosome disassembly are coordinated responses to pemphigus autoantibodies. J Biol Chem 2006, 281:7623-7634

20. Delva E, Jennings JM, Calkins CC, Kottke MD, Faundez V, Kowalczyk AP: Pemphigus vulgaris IgG-induced desmoglein-3 endocytosis and desmosomal disassembly are mediated by a clathrin- and dynaminindependent mechanism. J Biol Chem 2008, 283:18303-18313

21. Jolly PS, Berkowitz P, Bektas M, Lee H-E, Chua M, Diaz LA, Rubenstein DS: p38MAPK signaling and desmoglein-3 internalization are linked events in pemphigus acantholysis. J Biol Chem 2010, 285 8936-8941

22. Spindler V, Heupel W-M, Efthymiadis A, Schmidt E, Eming R, Rankl C, Hinterdorfer $\mathrm{P}$, Müller T, Drenckhahn D, Waschke J: Desmocollin 3-mediated binding is crucial for keratinocyte cohesion and is impaired in pemphigus. J Biol Chem 2009, 284:30556-30564

23. Spindler V, Vielmuth F, Schmidt E, Rubenstein DS, Waschke J: Protective endogenous cyclic adenosine 5 '-monophosphate signaling triggered by pemphigus autoantibodies. J Immunol 2010, 185:68316838

24. Gliem M, Heupel W-M, Spindler V, Harms GS, Waschke J: Actin reorganization contributes to loss of cell adhesion in pemphigus vulgaris. Am J Physiol Cell Physiol 2010, 299:C606-C613

25. Boukamp P, Petrussevska RT, Breitkreutz D, Hornung J, Markham A, Fusenig NE: Normal keratinization in a spontaneously immortalized aneuploid human keratinocyte cell line. J Cell Biol 1988, 106:761-771

26. Kitajima $Y$, Aoyama $Y$, Seishima M: Transmembrane signaling for adhesive regulation of desmosomes and hemidesmosomes, and for cell-cell detachment induced by pemphigus IgG in cultured keratinocytes: involvement of protein kinase C. J Invest Dermatol Symp Proc 1999, 4:137-144

27. Osada K, Seishima M, Kitajima Y: Pemphigus IgG activates and translocates protein kinase $\mathrm{C}$ from the cytosol to the particulate/ cytoskeleton fractions in human keratinocytes. J Invest Dermatol 1997, 108:482-487

28. Denning MF: Epidermal keratinocytes: regulation of multiple cell phenotypes by multiple protein kinase $\mathrm{C}$ isoforms. Int J Biochem Cell Biol 2004, 36:1141-1146 
29. Jirousek MR, Goekjian PG: Protein kinase C inhibitors as novel anticancer drugs. Exp Opin Invest Drugs 2001, 10:2117-2140

30. Ishii K, Harada R, Matsuo I, Shirakata Y, Hashimoto K, Amagai M: In vitro keratinocyte dissociation assay for evaluation of the pathogenicity of anti-desmoglein $3 \mathrm{lgG}$ autoantibodies in pemphigus vulgaris. J Invest Dermatol 2005, 124:939-946

31. van der Wier G, Pas HH, Jonkman MF: Experimental human cell and tissue models of pemphigus. Dermatol Res Pract 2010:143871, 2010

32. Anhalt GJ, Labib RS, Voorhees JJ, Beals TF, Diaz LA: Induction of pemphigus in neonatal mice by passive transfer of IgG from patients with the disease. N Engl J Med 1982, 306:1189-1196

33. Pelacho B, Natal C, Espana A, Sanchez-Carpintero I, Iraburu MJ, Lopez-Zabalza MJ: Pemphigus vulgaris autoantibodies induce apoptosis in HaCaT keratinocytes. FEBS Lett 2004, 566:6-10

34. Lanza A, Cirillo N, Rossiello R, Rienzo M, Cutillo L, Casamassimi A, de Nigris F, Schiano C, Rossiello L, Femiano F, Gombos F, Napoli C: Evidence of key role of Cdk2 overexpression in pemphigus vulgaris. J Biol Chem 2008, 283:8736-8745

35. Garrod DR, Berika MY, Bardsley WF, Holmes D, Tabernero L: Hyperadhesion in desmosomes: its regulation in wound healing and possible relationship to cadherin crystal structure. J Cell Sci 2005, 118: 5743-5754

36. Kimura TE, Merritt AJ, Garrod DR: Calcium-independent desmosomes of keratinocytes are hyper-adhesive. J Invest Dermatol 2007, 127:775-781

37. Wallis S, Lloyd S, Wise I, Ireland G, Fleming TP, Garrod D: The alpha isoform of protein kinase $\mathrm{C}$ is involved in signaling the response of desmosomes to wounding in cultured epithelial cells. Mol Biol Cell 2000, 11:1077-1092

38. Thomason HA, Scothern A, McHarg S, Garrod DR: Desmosomes: adhesive strength and signalling in health and disease. Biochem $J$ 2010, 429:419-433

39. Denning MF, Guy SG, Ellerbroek SM, Norvell SM, Kowalczyk AP, Green KJ: The expression of desmoglein isoforms in cultured human keratinocytes is regulated by calcium. serum, and protein kinase C. Exp Cell Res 1998, 239:50-59

40. Sánchez-Carpintero I, España A, Pelacho B, López Moratalla N, Rubenstein DS, Diaz LA, López-Zabalza MJ: In vivo blockade of pemphigus vulgaris acantholysis by inhibition of intracellular signal transduction cascades. Br J Dermatol 2004, 151:565-570

41. Cirillo N, Lanza A, Prime SS: Induction of hyper-adhesion attenuates autoimmune-induced keratinocyte cell-cell detachment and processing of adhesion molecules via mechanisms that involve PKC. Exp Cell Res 2010, 316:580-592

42. Batlle E, Verdú J, Domínguez D, de Mont Llosas M, Díaz V, Loukili N Paciucci R, Alameda F, de Herreros AG: Protein kinase C-alpha activity inversely modulates invasion and growth of intestinal cells. J Biol Chem 1998, 273:15091-15098

43. Masur K, Lang K, Niggemann B, Zanker KS, Entschladen F: High PKC (alpha) and low E-cadherin expression contribute to high migratory activity of colon carcinoma cells. Mol Biol Cell 2001, 12:19731982

44. Bass-Zubek AE, Hobbs RP, Amargo EV, Garcia NJ, Hsieh SN, Chen X, Wahl JK, Denning MF, Green KJ: Plakophilin 2: a critical scaffold for $\mathrm{PKC} \alpha$ that regulates intercellular junction assembly. J Cell Biol 2008, 181:605-613

45. Green KJ, Getsios S, Troyanovsky S, Godsel LM: Intercellular junction assembly, dynamics, and homeostasis. Cold Spring Harbor Perspect Biol 2010, 2:a000125

46. Menon GK, Grayson S, Elias PM: Ionic calcium reservoirs in mammalian epidermis: ultrastructural localization by ion-capture cytochemistry. J Invest Dermatol 1985, 84:508-512

47. Menon GK, Elias PM, Lee SH, Feingold KR: Localization of calcium in murine epidermis following disruption and repair of the permeability barrier. Cell Tissue Res 1992, 270:503-512

48. Mauro T, Bench G, Sidderas-Haddad E, Feingold K, Elias P, Cullander $\mathrm{C}$ : Acute barrier perturbation abolishes the $\mathrm{Ca} 2+$ and $\mathrm{K}+$ gradients in murine epidermis: quantitative measurement using PIXE. J Invest Dermatol 1998, 111:1198-1201

49. Waschke J, Menendez-Castro C, Bruggeman P, Koob R, Amagai M, Gruber HJ, Drenckhahn D, Baumgartner W: Imaging and force spectroscopy on desmoglein 1 using atomic force microscopy reveal multivalent $\mathrm{Ca}(2+)$-dependent, low-affinity trans-interaction. J Membr Biol 2007, 216:83-92

50. Garrod D, Kimura TE: Hyper-adhesion: a new concept in cell-cell adhesion. Biochem Soc Trans 2008, 36:195-201

51. Yuspa SH, Kilkenny AE, Steinert PM, Roop DR: Expression of murine epidermal differentiation markers is tightly regulated by restricted extracellular calcium concentrations in vitro. J Cell Biol 1989, 109: 1207-1217

52. Kitajima $Y$, Inoue S, Yaoita $\mathrm{H}$ : Effects of pemphigus antibody on the regeneration of cell-cell contact in keratinocyte cultures grown in low to normal Ca++ concentration. J Invest Dermatol 1987, 89:167-171

53. Hennings H, Michael D, Cheng C, Steinert P, Holbrook K, Yuspa SH: Calcium regulation of growth and differentiation of mouse epidermal cells in culture. Cell 1980, 19:245-254

54. Getsios S, Simpson CL, Kojima S-I, Harmon R, Sheu LJ, Dusek RL, Cornwell M, Green KJ: Desmoglein 1-dependent suppression of EGFR signaling promotes epidermal differentiation and morphogenesis. J Cell Biol 2009, 185:1243-1258 